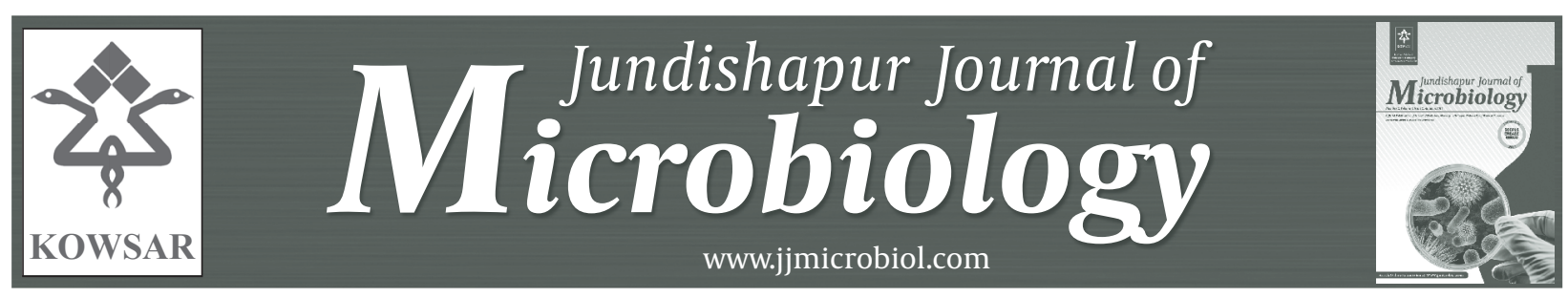

\title{
Molecular Cloning and Expression of the Leishmania infantum KMP-11 Gene
}

\author{
Saied Soflaei ${ }^{1}$, Abdolhossein Dalimi ${ }^{1 *}$, Fatemeh Ghafarifar ${ }^{1}$ \\ ${ }^{1}$ Department of Parasitology, Faculty of Medical Sciences, Tarbiat Modares University, Tehran, IR Iran \\ * Corresponding author:Abdolhossein Dalimi, Department of Parasitology, Faculty of Medical Sciences, Tarbiat Modares University, P.O.Box: 14115-331, Teh- \\ ran, IR Iran. Tel: +98-2182883838, Fax: +98-02182884555, E-Mail:dalimi_a@modares.ac.ir
}

\section{A B S T R A C T}

Background: Visceral leishmaniasis (Kala-azar) is one of the most serious tropical diseases, and it can lead to death. The kinetoplastid membrane protein-11 (KMP-11) is highly conserved in all stages of the Leishmania life cycle.

objectives: In the present study, the KMP-11 gene was extracted from Leishmania infantum and then, cloned and expressed in an expression vector.The main objective of this study was to provide an introduction to DNA vaccine production against visceral leishmaniasis.

Materials and Methods: DNA was extracted from L. infantum (MHOM/TN/80/IPI1), and amplified by PCR and a specific primer. Afterwards the purified PCR products were successfully ligated into the pTZ57R/T plasmid vector. The pcDNA3 plasmid was used as an expression vector and the KMP-11 gene subcloned into this plasmid. The pTKMP-11 plasmid was digested by restriction enzymes to confirm cloning of this gene in the pTZ57R/T plasmid. In the last step, the subcloned gene was expressed in a eukaryotic cell.

Results: The KMP-11 gene was successfully subcloned in pcDNA3 as a eukaryotic expression vector. Recombinant KMP-11 protein was confirmed by the reverse transcriptase polymerase chain reaction (RT-PCR) method.

Conclusions: The results of the present study will increase our knowledge about molecular cloning and expression of the L. infantum KMP-11 gene, and this may be used as an effective target for controlling visceral leishmaniasis.

Keywords: Leishmania infantum; KMP-11; Plasmids

Copyright @ 2013, Kowsar Corp.; Published by Kowsar Corp.

\section{Background}

Leishmaniasis is an important public health problem all over the world. Leishmaniasis, malaria, schistosomiasis, filariasis, trypanosomiasis and tuberculosis, are considered by the World Health Organization (WHO) to be six of the most important tropical diseases (1). Leishmaniasis has been reported in 88 countries around the world and the prevalence of the disease is estimated to be approximately 12 million annually, in addition, approximately 350 million people are at risk of catching the disease $(1,2)$.

Visceral leishmaniasis (Kala-azar) is characterized by the presence of; fever, splenomegaly, hepatomegaly, swollen lymph nodes and weight loss, depending on the pathogenicity of the Leishmania species and the

Article type: Research Article; Received: 13 Mar 2012, Revised: 22 May 2012, Accepted: 27 May 2012; DOI: 10.5812/jjm.4798

-Implication for health policy/practice/research/medical education:

The present results about molecular cloning and expression of the L. infantum KMP-11 gene could be used as an effective target for controlling visceral leishmaniasis.

Please cite this paper as:

Soflaei S, Dalimi A, Ghafarifar F. Molecular Cloning and Expression of the Leishmania infantum KMP-11 Gene. Jundishapur J Microbiol. 2013; 6(2): 132-137. DOI: 10.5812/jjm.4798

Copyright @ 2013 Ahvaz Jundishapur University of Medical Sciences; Published by Kowsar Corp.

This is an Open Access article distributed under the terms of the Creative Commons Attribution License(http://creativecommons.org/licenses/by/3.0), which permits unrestricted use, distribution, and reproduction in any medium, provided the original work is properly cited. 
host's immune response against the parasite $(3,4)$. This disease can lead to death in $90 \%$ of cases, if the patient is left without any treatment. The drugs which are currently used as treatment for leishmaniasis cannot be handled easily due to a number of problems including; high toxicity, and various side effects (4). Therefore, efforts to introduce a new protein for vaccine production are currently being considered. Up to now, various antigens such as TSA, and P4 LACK, have been evaluated for vaccine development (5-9). In this regard, a new molecule common in Leishmania species, is the $11 \mathrm{KD}$ protein of the membrane kinetoplastid surface or KMP-11 (10). The KMP-11 is highly conserved and has common characteristics in most of the Kinetoplastidae family (11). In the beginning, these molecules were called associated proteins of lipophosphogly can and then called kinetoplastid membrane protein-11 $(12,13)$. KMP-11 was isolated from Leishmania donovani and previously characterized by Jardim et al. in 1995 (12). Some findings suggest that the KMP-11 protein may be involved with mobility in both the parasite and in binding to the host cell. So, it could be considered as a candidate for vaccine production (14).

\section{Objectives}

The aim of this present study was to increase our knowledge concerning molecular cloning and expression of the KMP-11 gene of L. infantum. In the present study the KMP-11 gene of $L$. infantum encoding KMP-11 proteinswas cloned into a pcDNA3 expression vector, and transfected into Chinese hamster ovary ( $\mathrm{CHO}$ ) eukaryote cells. The main objective of the study was to provide an introduction for DNA vaccine production against visceral leishmaniasis.

\section{Material and Methods}

\subsection{Parasite}

Promastigotes of L. infantum (MHOM/TN/80/IPI1) were prepared from the Pasteur Institute of Iran (Tehran, Iran). Promastigotes were cultured in a RPMI1640 medium and supplemented with 10\% FCS (Fetal Calf Serum, Sigma-Aldrich, Germany). This culture was then incubated at $24 \pm 1^{\circ} \mathrm{C}$.

\subsection{Genomic DNA Extraction}

Genomic DNA was extracted from the promastigotes of Leishmania by a DNA genomic extraction kit (Bioneer, Hamburg, Germany), this process was carried out according to the manufacturer's protocol. DNA concentration and quality was assessed by both UV absorbance and electrophoresis on the $1 \%$ agarose gel.

\subsection{DNA Amplification}

The PCR reaction was performed in a $25 \mu \mathrm{l}$ volume containing; $5 \mu \mathrm{l}$ of DNA genomic as a template, $1 \mu \mathrm{l}$ of each primer, $2 \mu \mathrm{l}$ of a PCR master mix, and $16 \mu \mathrm{l}$ of distilled water. Sense and antisense oligonucleotide primers were designed based on DNA sequences of KMP-11 that were recorded in GenBank. Forward primer: AAGCTTATGGCCACCACGTACGAGGAG and reverse primer:GAATTCTTACTTGGATGGGTACTGCGCAGC. The forward primer contains a HindIII restriction site and the reverse primer contains an EcoRI restriction site 6 nucleotides. The PCR procedure included: $94^{\circ} \mathrm{C}$ for two minutes as initial denaturation, 35 cycles at $94^{\circ} \mathrm{C}$ for 30 seconds, $59^{\circ} \mathrm{C}$ for 30 seconds, $72^{\circ} \mathrm{C}$ for 30 seconds and then $72^{\circ} \mathrm{C}$ for seven minutes as a final extension. Finally, the PCR products were analyzed by electrophoresis on a $2 \%$ agarose gel. KMP-11 gene fragments were purified from the gel using a gel purification kit (Bioneer, Hamburg, Germany).

\subsection{Ligation and Transformation}

Ligation of the KMP-11 gene into the PTZ57R plasmid was performed using an InsTA cloneTM PCR product cloning kit (Fermentas $囚$, Germany). Ligation reaction was prepared in a $30 \mu \mathrm{l}$ volume containing; $5 \mu \mathrm{l}$ of template (DNA extraction product), $3 \mu$ of pTZ57R plasmid, $5 \mu \mathrm{l}$ of $5 \mathrm{x}$ ligation buffer, $1 \mu \mathrm{l}$ of T4 ligase and $15 \mu \mathrm{l}$ of distilled water. This reaction was first incubated at $22^{\circ} \mathrm{C}$ for an hour and then at $4^{\circ} \mathrm{C}$ for 16 hours. The competent cells were prepared from the TOP10 strain of Escherichia coli bacteria using the calcium chloride method. E. coli $100 \mu \mathrm{l}$, was cultured with $5 \mathrm{ml}$ of new Luria-Bertani and then incubated at $37^{\circ} \mathrm{C}$ for 14 hours. The next day, $200 \mu \mathrm{l}$ of these cells were cultured in $10 \mathrm{ml}$ of LB broth and incubated at $37^{\circ} \mathrm{C}$ for three hours. After incubation, the culture was centrifuged at $7000 \mathrm{rpm}$ and $4^{\circ} \mathrm{C}$ for 10 minutes. The supernatant was discharged and then $3-4 \mathrm{ml}$ of cold calcium chloride $(100 \mathrm{mM})$ was added to the pellet and mixed gently. The suspension was centrifuged at 7000rpm and $4^{\circ} \mathrm{C}$ for 10 minutes.

The supernatant was discharged and $250 \mu$ l of cold calcium chloride added to the pellet and mixed gently before being incubated on ice pieces for one hour. Following this, $10 \mu \mathrm{l}$ of the ligation product was added to this suspension and incubated on ice pieces for 30 minutes. Then, the suspension for heat shock was incubated at $42^{\circ} \mathrm{C}$ for 90 seconds and then immediately transferred onto ice. Subsequently $500 \mu$ l of LB broth, without any antibiotic, was added and incubated at $37^{\circ} \mathrm{C}$ for one hour. These cells were cultured on plates of Luria-Bertani (LB) agar medium containing; 100mg/ $\mathrm{mL}$ of ampicillin, $200 \mathrm{mg} / \mathrm{mL}$ of IPTG and $20 \mathrm{mg} / \mathrm{mL}$ of $\mathrm{X}$-Gal. The plates were incubated at $37^{\circ} \mathrm{C}$ for 16 hours.

Recombinant plasmids (pTKMP-11) were extracted from white colonies according to the protocol for the 
plasmid extraction kit (Bioneer, Hamburg, Germany). The recombinant plasmid (pTKMP11), pTZ57R (negative control) and pcDNA3(expression vector) were digested by EcoRI and HindIII enzymes. The double digestion reactions were prepared in the same way for each in $220 \mu \mathrm{l}$ volumes containing $80 \mu \mathrm{l}$ of the plasmid extraction product, $88 \mu \mathrm{l}$ of water, $44 \mu \mathrm{l}$ of tango buffer (Fermentas ${ }^{\circledR}$, Germany), $4 \mu \mathrm{l}$ of EcoRI and $4 \mu \mathrm{l}$ of HindIII enzymes. These reactions were incubated at $37^{\circ} \mathrm{C}$ for 16 hours. The products of digestion were analyzed by electrophoresis on $0.8 \%$ agarose gel. The bands belonging to the KMP-11 fragment and digested expression plasmids (pcDNA3) were purified from the agarose gel by a gel purification kit (Bioneer, Hamburg, Germany). KMP-11 fragments were purified from the gel and sent to the GenFanaVaran $®$ Company (Iran, Tehran) for sequencing.

\subsection{Subcloning in pcDNA3 Expression Vector}

The KMP-11 gene was ligated into digested pcDNA3 expression vectors using T4DNA ligase enzymes. Recombinant plasmid pcKMP-11 was transformed into competent E.coli cells and recovered in LB broth medium free of antibiotic at $37^{\circ} \mathrm{C}$ for one to three hours. Then, it was sub-cultured on new LB agar medium and incubated at $37^{\circ} \mathrm{C}$ for 16 hours. Recombinant plasmids (pcKMP-11) were extracted from E. coli by a Bioneer plasmid extraction kit according to the manufacturer's instructions. The extracted plasmids from the white colony were digested by EcoRI and HindIII enzymes and electrophoresis occurred on $0.8 \%$ agarose gel.

\subsection{Expression of Recombinant Protein}

In order to carry out transfecting, $\mathrm{CHO}$ eukaryote cells were used as host cells for recombinant expression plasmids (pTKMP-11). The CHO cells were cultured under sterile conditions in DMEM (Gibco) medium supplemented with $5 \% \mathrm{FCS}$ under $37^{\circ} \mathrm{C}$ with $5 \% \mathrm{CO} 2$ conditions.

\subsection{RNA Extraction and Reverse Transcriptase Procedure}

For gene transcription confirmation at the level of mRNA, a RT-PCR kitwas used. The total RNA isolated from the cells by RNXTM-plus Isolation RNA kit (Fermentas, Germany). RTPCR was performed according to the manufacturer's protocol using a RT PCR kit (Fermentas, Germany) then the result was electrophoresis on $2 \%$ agarose gel.

\section{Results}

The size of the amplified KMP-11 gene of L. infantum in our study was similar to earlier predictions. A 279 bp DNA fragment was identified following agarose gel electrophoresis of the PCR products (Figure 1). The PCR products were ligated into a pTZ57R/T standard cloning vector. The plasmid (pTKMP-11) was transformed successfully into E. coli. The recombinant plasmids from the white colony were sequenced and compared with sequences in the GenBank.The KMP-11 gene sequence was $97-99 \%$ identical with that of other organisms (Table 1 and Table 2).

The sequence of the KMP-11 gene from L. infantum in our study was submitted to GenBank with the accession number: JF422108.1. The extracted plasmids from the white colony were digested by EcoRI and HindIII enzymes and delectrophoresis on $0.8 \%$ agarose gel (Figure 2 ). At the next step, this gene was successfully cloned into pcDNA3 expressing eukaryote vectors and transformed into E. coli bacteria. The extracted expression plasmids digested by EcoRI and HindIII enzymes are shown in Figure 3 . The expression plasmids pTKMP-11, were transfected successfully into the $\mathrm{CHO}$ cells and following RNA extraction, they were confirmed by RTPCR methods, finally the results were electrophoresis on $2 \%$ agarose gel (Figure 4).

Figure 1. Electrophoresis of PCR Products for KMP-11 (279bp) Fragment of L. infantumfi Amplication. A; KMP-11 fragments of L. infantum

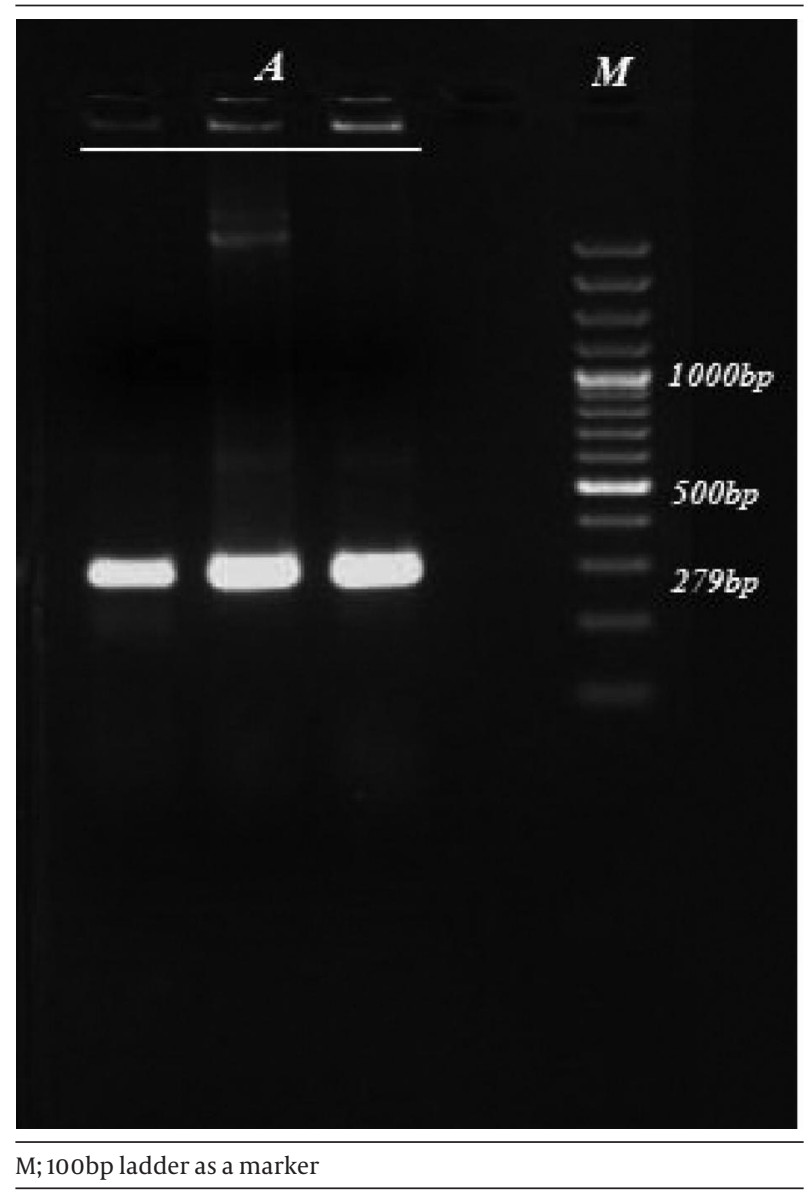




\begin{tabular}{|c|c|c|c|c|}
\hline & Strain & Length of Gene & Accession No. $^{a}$ & Similarity, \% \\
\hline L.infantuma & MHOM/TN/80/IPI1 & 279bp & JF422108.1 & 100 \\
\hline L.infantum & JPCM5 & 279bp & XM_001468995.1 & 99 \\
\hline L.major & Friedlin & 279bp & FR796431.1 & 99 \\
\hline L.infantum & LEM78 MON-1 & 279bp & X95627.1 & 99 \\
\hline L.donovani & BPK282A1 & 279bp & FR799622.2 & 99 \\
\hline L.tropica & - & 279bp & АJ000078.1 & 99 \\
\hline L.mexicana & MHOM/GT/2001/U1103 & 279bp & FR799587.1 & 99 \\
\hline L.amazonensis & IFLA/BR/67/PH8 & 279bp & AF193432.1 & 99 \\
\hline L.panamensis & M/HOM/PA/71LS94/6/7 & 279bp & U93582.1 & 99 \\
\hline L.panamensis & $\mathrm{M} / \mathrm{HOM} / \mathrm{PA} / 71 \mathrm{LS} 94 / 5 / 7$ & 279bp & U93578.1 & 99 \\
\hline L.guyanensis & MHOM/BR/75/M-4147 & 279bp & AF026141.1 & 98 \\
\hline L. braziliensis & MHOM/BR/75/M-2903 & 279bp & AF026136.1 & 98 \\
\hline T. cruzi & CL Brener & 279bp & XM_803773.1 & 81 \\
\hline T. brucei & TREU927 & 279bp & XM_822498.1 & 81 \\
\hline T.rangeli & 5048 & 279bp & DQ194343.1 & 81 \\
\hline Crithidia sp. & CJP-2005 & 279bp & DQ194339.1 & 81 \\
\hline
\end{tabular}

a Accession number JF422108.1 were compared with 16 sequences of other organisms submitted to GenBank

Figure 2. Recombinant Plasmid (pTKMP-11) Digested by EcoRI and HindIII Enzymes and Electrophoresis on 0.8\% Agarose Gel.

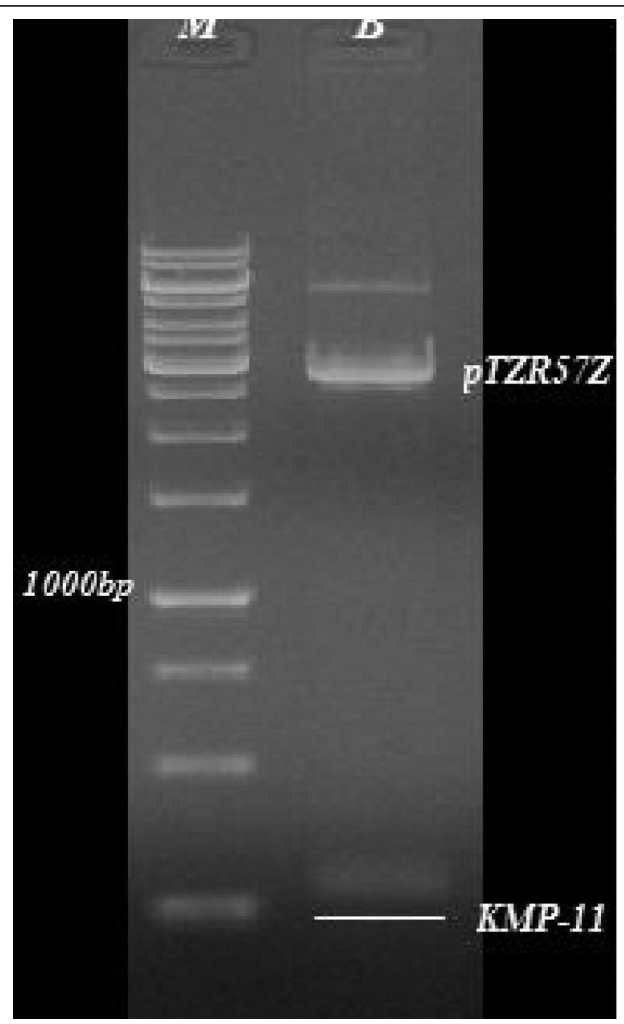

M, 1kb ladder as marker; B, bands of KMP-11 fragment (279bp) and plasmid after digestion.
Table 2. Protein Encoded by the KMP-11 Gene From L. infantum Compared With Other Records in GenBank From Different Countries.

\begin{tabular}{|c|c|c|c|}
\hline & Protein ID & Amino Acids & Country \\
\hline L. infantum & AEK80413.1 & 92 & Iran \\
\hline L. infantum & XP_001469032 & 92 & England \\
\hline L. infantum & CAA64883 & 92 & Spain \\
\hline L. major & XP_843328 & 92 & USA \\
\hline L.donovani & AAB33127 & 92 & England \\
\hline L.donovani & S53442 & 92 & Canada \\
\hline L. tropica & CAA03902 & 92 & Spain \\
\hline L.panamensis & AAC61837 & 92 & Columbia \\
\hline L. amasonensis & AAG32958 & 92 & Brazil \\
\hline L.guyanensis & AAB94115 & 92 & Columbia \\
\hline $\begin{array}{l}\text { Tryponosoma } \\
\text { rangeli }\end{array}$ & ABA42053 & 92 & Columbia \\
\hline Crithidiasp & ABA42050 & 92 & Columbia \\
\hline
\end{tabular}

\section{Discussion}

To date, various antigens such as TSA, LACK and P4 have been evaluated to assess their potential for DNA or recombinant vaccine development against leishmaniasis (5-9). In addition, the KMP-11 protein has been proposed as a candidate for vaccine production against L. infantum (14). The sequence of the L. infantum KMP-11 gene in the present study (accession no: JF422108.1), was 98-99\% identical with 
other Leishmania species. Translation from the sequence of this gene product produces a protein containing 92 amino acids and it has an isoelectric point of 4.8 , which is associated with the membrane of the promastigote.

Figure 3. Electrophoresis of Recombinant Vector (pcKMP-11) After Digestion by EcoRI and HindIII Enzymes With 1kb (M1) and 10obp (M2) Ladders as Markers.

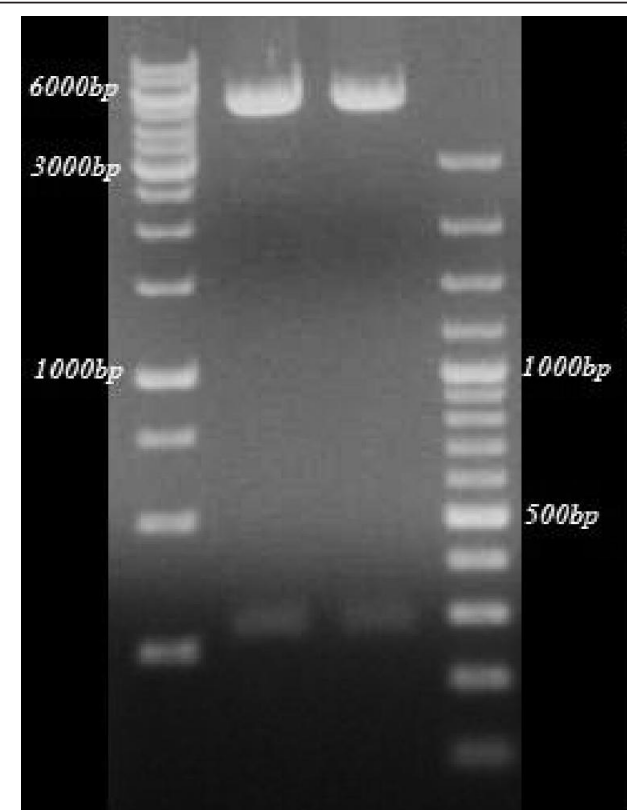

A, bands of KMP-11 fragment (279bp) and plasmid (pcDNA3) after digestion

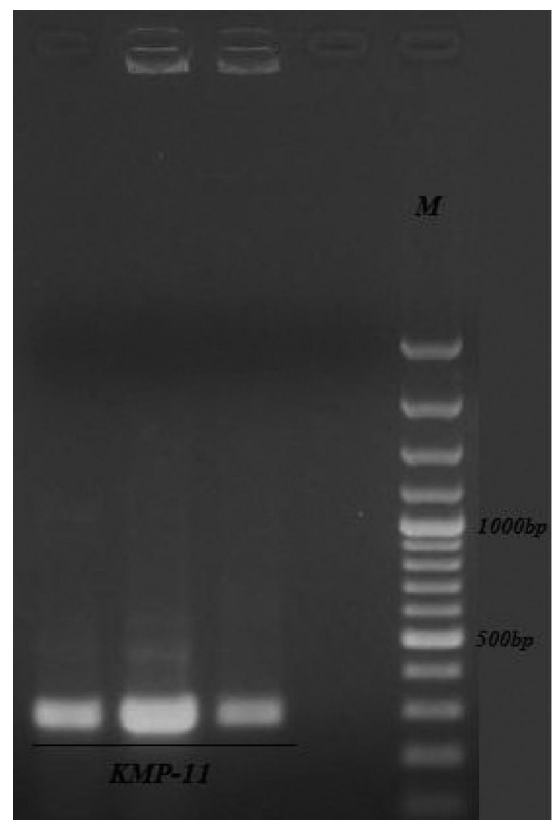

Figure 4. Electrophoresis of RT-PCR Products of the KMP-11 Gene From L. infantum. Three bands of KMP-11 fragment (279bp); M, 100bp ladder as marker.
According to the Berberich et al. study, the transcription of the KMP-11 gene results invariable sized mRNA with $0.5 \mathrm{~kb}$ in Trypanosoma cruzi, $0.8 \mathrm{~kb}$ and $1.3 \mathrm{~kb}$ in T. brucei and L. infantum, respectively (10). Proteins in most of the kinetoplastids have common characteristics such as weight; $11 \mathrm{KD}$ molecular and expression at all stages of the parasite's life cycle(14). Immunofluorescence studies suggest that the KMP-11 protein is located mainly along the flagellum and flagellar base of the parasites. Parasites like L. infantum, T. congolense and T. brucei, have been shown to be immunoreactive primarily along the flagellum and flagellar pocket, while that presented at Leishmania donovani's flagellar location differs, as it exhibited a pattern of fluorescence which was more widely dispersed throughout the cell $(10,11)$.

At present, the biological function of the KMP-11 proteinis not yet fully understood, however, it clearly has three immunological roles; B-cell immunostimulatory, inducer lymphocyte proliferation and response cytotoxic and immunoprotective in animal models (15). The KMP-11 protein could induce the proliferation of $\mathrm{T}$ lymphocytes. Tolson et al. showed that the KMP-11 protein in L. donovani is a potent stimulator of CD4+, CD8in mice immunized with KMP-11 proteins (16). In addition, according to Basu et al. this protein is an excellent target for T cytotoxic lymphocytes (CD8+) and natural killer cells (NK). It has been revealed that KMP-11 induces significant production of IFN- $\gamma$ cytokine from T-helper lymphocytes (17). Moreover, Trujillo et al. showed that the subclasses of immunoglobulins involved in the response fronts of KMP-11 in Leishmania, in order of reactivity are; IgG1, IgG3, IgG2 and IgG4 (18).

Considering the aforementioned findings, KMP-11 has been used previously for immunotherapy and immunization against leishmaniasis. Maranon et al. immunized transgenic mice with an $\mathrm{A} 2 / \mathrm{Kb}$ fusion protein composed of the heat shock proteins HSP70 and KMP-11 in T. cruzi that induces a cytotoxic response against cells expressing the KMP-11 in the parasite (19). Moreover, Planelles et al. have found that the fusion protein HSP70/KMP-11, is capable of acting as a stimulator for mature mouse dendritic cells and the consequent production of interleukin 12 (IL-12) and tumor necrosis factor (TNF $\alpha$ ) (20). In addition, Ramirez et al. showed that immunization of BALB/c mice with an attenuated strain of Toxoplasma gondii expressing the protein Leishmania KMP-11, induces a specific immune response and immunoprotective in such animals (21). The study of Berberich et al, showed that immunization of mice with murine dendritic cells pulsed with a mixture of recombinant Leishmania antigens, including KMP-11 proteins, are able to control $L$. major infections (22).

In conclusion, the recombinant plasmid of pTKMP-11 that was successfully constructed in the present study could be used for future DNA vaccine production 
against leishmaniasis.

\section{Acknowledgements}

The authors wish to thank Dr. Sarvi for his scientific assistance. The assistance of the parasitology department staffs is greatly appreciated.

\section{Financial Disclosure}

The present work is part of MSc thesis, supported financially only by Medical Sciences Faculty of Tarbiat Modares University.

\section{Funding/Support}

The authors acknowledge the Medical Sciences Faculty of Tarbiat Modares University for their financial support to this research work.

\section{Authors' Contribution}

S. Soflaei was main researcher; A. Dalimi was supervisor of the thesis and corresponding author; F. Ghafarifar was advisor of the thesis.

\section{References}

1. Alexander J, Satoskar AR, Russell DG. Leishmania species: models of intracellular parasitism. J Cell Sci.1999;112(Pt 18):2993-3002.

2. Gangneux JP, Sulahian A, Garin YJ, Farinotti R, Derouin F. Therapy of visceral leishmaniasis due to Leishmania infantum: experimental assessment of efficacy of AmBisome. Antimicrob Agents Chemother. 1996;40(5):1214-8.

3. Pintado V, artin-Rabadan P, Rivera ML, Moreno S, Bouza E. Visceral leishmaniasis in human immunodeficiency virus (HIV)infected and non-HIV-infected patients. A comparative study. Medicine (Baltimore). 2001;80(1):54-73.

4. Sundar S, More DK, Singh MK, Singh VP, Sharma S, Makharia A, et al. Failure of pentavalent antimony in visceral leishmaniasis in India: report from the center of the Indian epidemic. Clin Infect Dis. 2000;31(4):1104-7.

5. Dondji B, Perez-Jimenez E, Goldsmith-Pestana K, Esteban M, McMahon-Pratt D. Heterologous prime-boost vaccination with the LACK antigen protects against murine visceral leishmaniasis. Infect Immun. 2005;73(8):5286-9.

6. Shaddel M, Oormazdi H, Akhlaghi L, Kazemi B, Bandehpour M. Cloning of Leishmania Major P4 Gene. Yahkhteh Med J. 2008;10(3):201-4.

7. Sujata K, Soong L, Colmenares M, Gold Smith K, Mc Mahon-Pratt D. The immunologically protective P4 Antigen of leishmania amastigotes. J Biol Chem. 2000;275:37789-97.

8. Tabatabaie F, Dalimi A, Sharifi Z, Hoseini AZ. Cloning and sequencing of Leishmania major thiol-specific-antioxidant antigen (TSA) gene. Iranian J Parasitol. 2007;2(4):30-41.
9. Tabatabaie F, Ghaffarifar F, Dalimi A, Sharifi Z, Hassan Z. Enhancement of cellular and antibody immune response to Leishmania major. Biochem Cell Arch. 2008;8(1):35-43.

10. Berberich C, Machado G, Morales G, Carrillo G, Jimenez-Ruiz A, Alonso $\mathrm{C}$. The expression of the Leishmania infantum KMP-11 protein is developmentally regulated and stage specific. Biochim Biophys Acta.1998;1442(2-3):230-7.

11. Stebeck CE, Baron GS, Beecroft RP, Pearson TW. Molecular characterization of the kinetoplastid membrane protein-11 from African trypanosomes. Mol Biochem Parasitol. 1996;81(1):81-8.

12. Jardim A, Hanson S, Ullman B, McCubbin WD, Kay CM, Olafson RW. Cloning and structure-function analysis of the Leishmania donovani kinetoplastid membrane protein-11. Biochem J. 1995;305(Pt 1):315-20.

13. Ramirez JR, Berberich C, Jaramillo A, Alonso C, Velez IV. Molecular and antigenic characterization of the Leishmania (Viannia) panamensis kinetoplastid membrane protein-11. Mem Inst Oswaldo Cruz. 1998;93(2):247-54.

14. Fuertes MA, Perez JM, Soto M, Lopez MC, Alonso C. calcium-induced conformational changes in Leishmania infantum kinetoplastid membrane protein-11. J Biol Inorg Chem. 2001;6(1):107-17.

15. Jensen AT, Gasim S, Ismail A, Gaafar A, Kurtzhals JA, Kemp M, et al. Humoral and cellular immune responses to synthetic peptides of the Leishmania donovani kinetoplastid membrane protein-11. Scand J Immunol.1998;48(1):103-9.

16. Tolson DL, Jardim A, Schnur LF, Stebeck C, Tuckey C, Beecroft $\mathrm{RP}$, et al. The kinetoplastid membrane protein 11 of Leishmania donovani and African trypanosomes is a potent stimulator of T-lymphocyte proliferation. Infect Immun. 1994;62(11):4893-9.

17. Basu R, Bhaumik S, Basu JM, Naskar K, De T, Roy S. Kinetoplastid membrane protein-11 DNA vaccination induces complete protection against both pentavalent antimonial-sensitive and -resistant strains of Leishmania donovani that correlates with inducible nitric oxide synthase activity and IL-4 generation: evidence for mixed Th1- and Th2-like responses in visceral leishmaniasis. J Immunol. 2005;174(11):7160-71.

18. Trujillo C, Ramirez R, Velez ID, Berberich C. The humoral immune response to the kinetoplastid membrane protein-11 in patients with American leishmaniasis and Chagas disease: prevalence of IgG subclasses and mapping of epitopes. Immunol Lett. 1999;70(3):203-9.

19. Maranon C, Thomas MC, Planelles L, Lopez MC. The immunization of $\mathrm{A} 2 / \mathrm{K}(\mathrm{b})$ transgenic mice with the KMP11-HSP70 fusion protein induces CTL response against human cells expressing the T. cruzi KMP11 antigen: identification of A2-restricted epitopes. Mol Immunol. 2001;38(4):279-87.

20. Planelles L, Thomas M, Pulgar M, Maranon C, Grabbe S, Lopez MC. Trypanosoma cruzi heat-shock protein-70 kDa,alone or fused to the parasite KMP11 antigen, induces functional maturation of murine dendritic cells. Immunol Cell Biol. 2002;80(3):241-7.

21. Ramirez JR, Gilchrist K, Robledo S, Sepulveda JC, Moll H, Soldati $D$, et al. Attenuated Toxoplasma gondii ts- 4 mutants engineered to express the Leishmania antigen KMP-11 elicit a specific immune response in BALB/c mice. Vaccine. 2001;20(3-4):455-61.

22. Berberich C, Ramirez-Pineda JR, Hambrecht C, Alber G, Skeiky YA, Moll H. Dendritic cell (DC)-based protection against an intracellular pathogen is dependent upon DC-derived IL-12 and can be induced by molecularly defined antigens. I Immunol. 2003;170(6):3171-9. 